\title{
Peak-Seeking Optimization of Trim for Reduced Fuel Consumption: Flight-Test Results
}

\author{
Nelson Brown, Jacob Schaefer ${ }^{\dagger}$ \\ NASA Dryden Flight Research Center, Edwards, California, 93523
}

\begin{abstract}
A peak-seeking control algorithm for real-time trim optimization for reduced fuel consumption has been developed by researchers at the National Aeronautics and Space Administration (NASA) Dryden Flight Research Center to address the goals of the NASA Environmentally Responsible Aviation project to reduce fuel burn and emissions. The peak-seeking control algorithm is based on a steepest-descent algorithm using a time-varying Kalman filter to estimate the gradient of a performance function of fuel flow versus control surface positions. In real-time operation, deflections of symmetric ailerons, trailing-edge flaps, and leading-edge flaps of an F/A-18 airplane (McDonnell Douglas, now The Boeing Company, Chicago, Illinois) are used for optimization of fuel flow. Results from six research flights are presented herein. The optimization algorithm found a trim configuration that required approximately 3 percent less fuel flow than the baseline trim at the same flight condition. The algorithm consistently rediscovered the solution from several initial conditions. These results show that the algorithm has good performance in a relevant environment.
\end{abstract}

\section{Nomenclature}

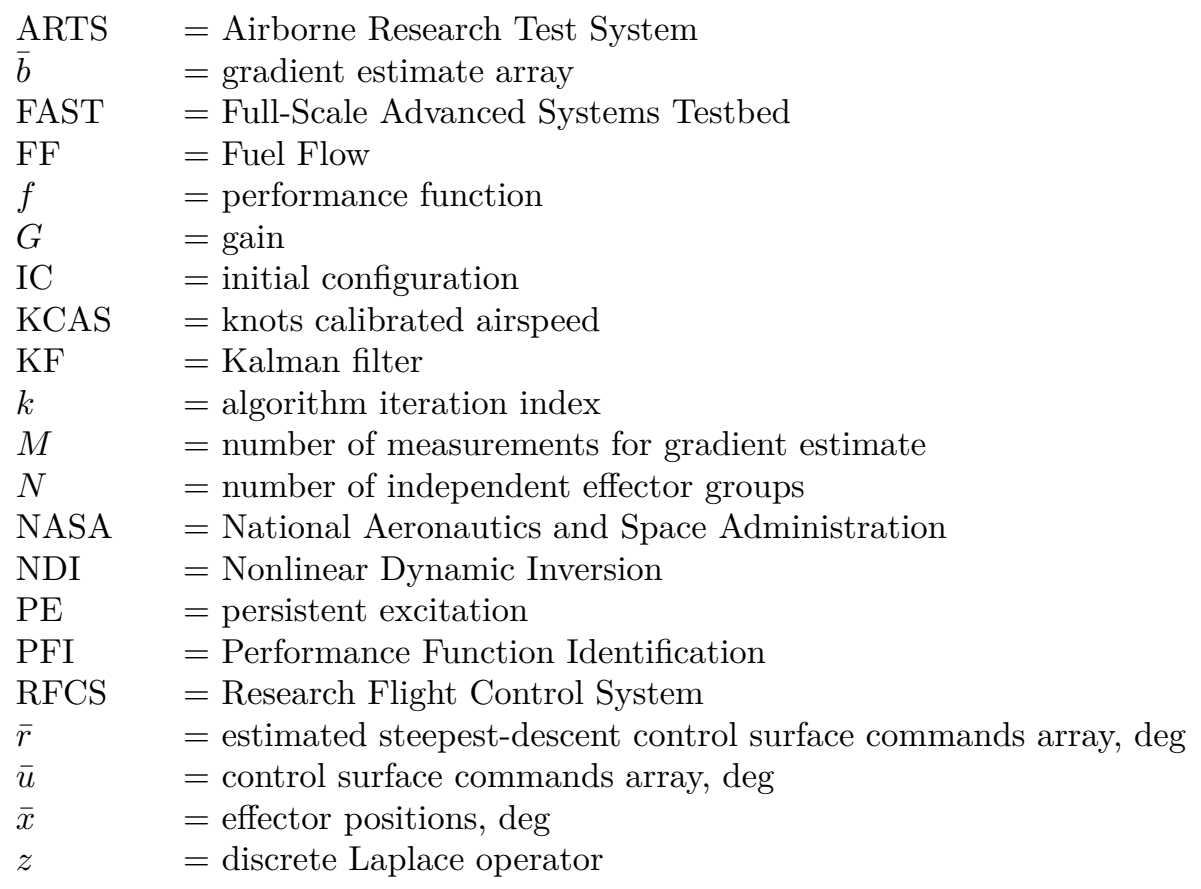

*Aerospace Engineer, Flight Controls and Dynamics Branch, P.O. Box 273/Mail Stop 4840D, nelson.brown@nasa.gov, AIAA Member.

${ }^{\dagger}$ Aerospace Engineer, Flight Controls and Dynamics Branch, P.O. Box 273/Mail Stop 4840D, jacob.schaefer@nasa.gov, AIAA Member. 


\section{Introduction}

The National Aeronautics and Space Administration (NASA) Environmentally Responsible Aviation project is seeking to mitigate the impact of aviation on the environment by reducing fuel consumption and emissions from aircraft. ${ }^{1}$ In 2011, United States air carriers, for domestic flights, consumed 12.1 billion gallons of fuel, releasing 114.6 million metric tons of carbon dioxide equivalent into the atmosphere. ${ }^{2,3}$ Small-percentage savings in fuel consumption rates for commercial aircraft will yield both large cost savings for airlines and reductions in emissions.

State-of-the-art airplanes make use of scheduled trim solutions designed a priori with model, wind-tunnel, and flight-test data. ${ }^{4,5,6}$ While scheduled trim solutions are usually designed with fuel efficiency as a high priority, assumptions must be made about how the aircraft will be operated. In practice, there are several possibilities for those assumptions to be violated. The aircraft may:

- be operating in off-nominal flight conditions,

- have subtle manufacturing differences compared to aircraft of the same type,

- have modifications such as winglets, external stores, blisters, engine upgrades, or repairs to damage,

- become more flexible as it ages, leading to a different wing shape under load.

In cases where the aerodynamics of the aircraft differ from the ideal, a small but meaningful improvement in fuel efficiency may be possible by adjusting the settings of the trim effectors. Various attempts have been made to improve upon scheduled trim solutions with real-time measurements.

Research regarding aircraft real-time trim optimization at the NASA Dryden Flight Research Center began in the 1990s with simulation studies and flight-testing of the Performance Seeking Control algorithm and the Adaptive Performance Optimization algorithm. The Performance Seeking Control algorithm was implemented and tested on an F-15 airplane (McDonnell Douglas, now The Boeing Company, Chicago, Illinois) and made use of stabilators and several effectors in the engines such as variable cowlings, inlet ramps, and nozzles. ${ }^{7,8,9,10}$ The Adaptive Performance Optimization algorithm was implemented and tested on an L-1011 airplane (Lockheed Corporation, now Lockheed Martin, Bethesda, Maryland) and made use of symmetric aileron deflection to reduce drag by approximately 1 percent in cruise. ${ }^{11,12}$ Outside of NASA, Krieger and Krstic have conducted simulation studies of a peak-seeking control algorithm, also known as extremum-seeking control, for optimizing airspeed for best possible aircraft endurance. ${ }^{13}$

A research engineering team at the NASA Dryden Flight Research Center set out to build upon those developments by implementing a trim optimization algorithm on an aircraft and testing the algorithm in a relevant flight environment. A peak-seeking control algorithm was implemented on a modified F/A-18 airplane (McDonnell Douglas, now The Boeing Company, Chicago, Illinois) for simulation studies and flight research. In real-time operation, deflections of symmetric ailerons, trailing-edge flaps, and leading-edge flaps, shown in Fig. 1, are used for optimization of fuel flow.

Peak-seeking control has been applied to a wide variety of uses. Closely related to the aircraft performance application that is the topic of this paper, several simulation studies have applied a peak-seeking control algorithm to the optimization of formation flight for fuel savings. ${ }^{14,15,16}$ The algorithm developed by Ryan and Speyer is the inspiration for the work presented in this paper, and it is also the algorithm used by Hanson. ${ }^{16}$ This algorithm has been demonstrated in other applications and solves some of the problems encountered in previous attempts to optimize trim in flight.

Prior to the flight-testing of the peak-seeking control algorithm presented in this paper, the algorithm was used in two simulation studies. First, the algorithm was implemented for the X-48B Blended Wing Body research aircraft (The Boeing Company, Chicago, Illinois) making use of the outboard elevons. ${ }^{17}$ The implementation on the X-48B research aircraft only directly controlled a single pair of effectors. Second, the algorithm was adapted for implemention on a modified F/A-18 airplane making use of three groups of effectors. ${ }^{18}$

The peak-seeking algorithm at the heart of this new real-time trim optimization approach was developed by Ryan and Speyer. ${ }^{14,19}$ This algorithm uses a time-varying Kalman filter to estimate the gradient of a performance function using in-flight measurements without the need for onboard models or lookup tables. Using this algorithm, a trim solution can be found that uses multiple control surfaces to minimize drag while keeping the moments balanced. As the number of effectors increases, the algorithm tuning becomes 


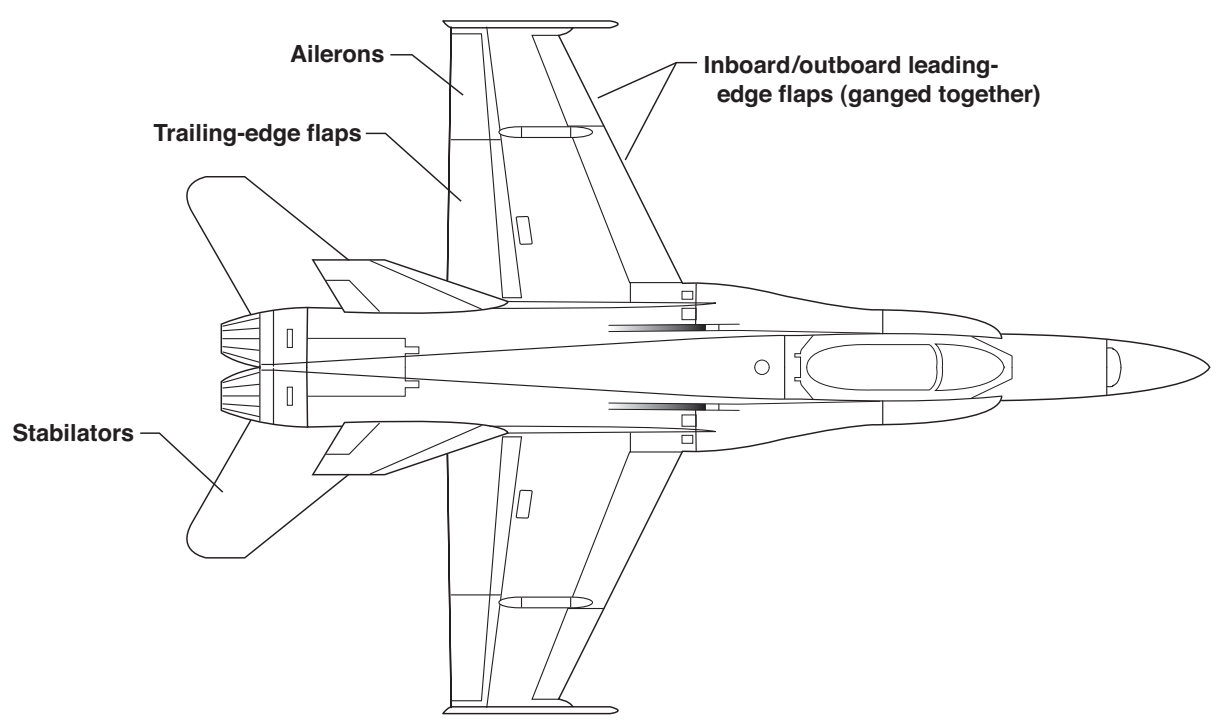

Figure 1. The F/A-18 aerodynamic control effectors.

more complicated and more difficult to design. For the F/A-18 implementation, the algorithm was changed substantially for the simultaneous direct tuning of three pairs of effectors.

The research discussed in this paper adds experimental results to the growing body of knowledge. While the scope of the experiment was limited to only two flight conditions of a single aircraft, the performance of the algorithm in a relevant environment complements the multiple simulation studies in the literature. The architecture of the algorithm and simulation predictions are contained in a companion paper. ${ }^{18}$ The paper at hand summarizes the flight-test results from the six research flights conducted in August through October of 2012, as well as presenting the flight-test techniques used to evaluate the algorithm.

\section{Airplane Description}

The NASA Full-Scale Advanced Systems Testbed (FAST) is a highly-modified F/A-18 airplane. A detailed description of the aircraft and its capabilities are available in another report. ${ }^{20}$ Excerpts of that report are summarized here for convenience. The FAST aircraft is primarily a flight controls research platform. The quad-redundant production flight control computers have been modified with an additional processor in each of the four channels to accommodate a Research Flight Control System (RFCS). In order to provide even greater computational and interface capabilities, the RFCS has been augmented with a dual-redundant Airborne Research Test System (ARTS) computer. Experimental software housed within the RFCS and ARTS computers can exercise full control over the flight control surfaces of the aircraft as well as the throttle. Pilot interfaces are provided for situational awareness, experiment selection, and configuration, and to facilitate transition between the production and research flight control systems. Flight control authority automatically reverts to the production control system in the event of a system failure or when a flight envelope constraint is violated.

\section{A. Instrumentation}

In addition to its research flight control capabilities, the FAST has been outfitted with extensive research instrumentation. Research instrumentation parameters as well as data from the production flight control systems and experimental software are recorded on-board the aircraft and telemetered to the ground for realtime control room monitoring and post-flight data analysis. The FAST has been heavily instrumented for a variety of flight research projects, including measurements of strains, accelerations, angular rates, pressures, control surface positions, angle of attack and angle of sideslip, and other parameters. A pair of research-grade fuel flow meters, one for each engine, was added for this experiment. This type of research-grade fuel flow meter was used previously on NASA research aircraft, including the X-29 Forward Swept Wing Technology Demonstrator (then Grumman Aircraft Corporation) and the F/A-18 airplane supporting projects such as 
the High Alpha Research Vehicle and Autonomous Formation Flight. ${ }^{21}$ The production F/A-18 airplane also has fuel flow meters, which exhibit more noise and have a coarser quantization compared to the research-grade flow meters. This report refers to measurements from both types of flow meters. Throughout this report they are called the "research flow meters" and the "production flow meters" to distinguish between the two types. The research flow meters measure the volumetric fuel flow, which is provided to the ARTS computer as feedback to the peak-seeking algorithm, recorded in the onboard instrumentation system, and telemetered to the mission control center. The production flow meters measure mass flow rate, which is available via the main aircraft 1553 bus. The power lever angle is the throttle position, which is also available via the main aircraft 1553 bus. Fuel temperature is measured at the fuel inlet to the engine with production sensors. The fuel temperature is recorded from the main aircraft 1553 bus for the purpose of converting volumetric flow rate to mass flow rate using the estimated fuel density. ${ }^{22}$

\section{B. Research Control Law Description}

The peak-seeking control algorithm is designed as an add-on to an existing aircraft control system. The FAST aircraft features a NASA-designed nonlinear dynamic inversion (NDI) inner-loop controller implemented in the research flight computer (ARTS). The architecture ${ }^{23}$ and flight-test results ${ }^{24}$ for this NDI control law are publicly available.

Research autopilots for altitude hold, airspeed hold, and wing leveler were added as outer loops around the NDI. The altitude hold and airspeed hold gains were tuned for shorter settling times and low tolerance for deviations when compared to the F/A-18 production autopilots. These aggressive gains were selected to improve test efficiency by shortening the time required for the aircraft to settle on a new trim configuration. Details about the architecture and interface between the algorithm and the NDI control laws are expounded in the companion paper. ${ }^{18}$

\section{The Peak-Seeking Algorithm}

The goal of the peak-seeking algorithm is to minimize a performance measurement, fuel flow, that is a function of surface positions. There is assumed to be a single, minimum-cost combination of surface positions; however, the performance function itself is unknown. The measurements of surface positions and fuel flow are noisy, which presents a challenge in finding the minimum in flight.

This peak-seeking control approach is based on a steepest-descent algorithm using a time-varying Kalman filter to estimate the gradient of the performance function. The algorithm directly adds biases to deflection of symmetric ailerons, trailing-edge flaps, and leading-edge flaps and holds those biases until the next iteration of the algorithm, approximately 30- to 120 -s intervals. The surface bias changes are rate-limited to $2 \mathrm{deg} / \mathrm{s}$, so the commands ramp to the new positions, minimizing transients. When the surface biases are changed, forces and moments on the aircraft are slightly out of balance, and the inner-loop controller and research autopilots must adjust the stabilators and throttle setting to maintain steady cruise flight. After the transient period, the system dwells at the new trim configuration to accumulate fuel flow measurements. The fuel flow is time-averaged over a 10-, 20-, or 40-s window.

Figure 2 illustrates the architecture of the peak-seeking algorithm. Time-averaged fuel flow is used as the performance function, $f$, and the effector positions are elements of the array $\bar{x}$. The Kalman filter (KF) generates an estimate of the gradients, array $\bar{b}$. The gradient estimate is multiplied by a simple gain, $G$, to generate the estimated steepest-descent control surface commands array, $\bar{r}$. A persistent excitation (PE) signal is added to $\bar{r}$ to create the command array, $\bar{u}$, for the next iteration. Since the fuel flow should be minimized, a negative gain is chosen in order to descend along the gradient.

In this way the deflections of symmetric ailerons, trailing-edge flaps, and leading-edge flaps of the F/A-18 airplane are directly optimized, and the horizontal stabilators and angle of attack are indirectly optimized. Details about the architecture of the peak-seeking algorithm, and its implementation on the F/A-18 airplane are expounded in the companion paper. ${ }^{18}$ For safety, the aileron commands of the algorithm were only allowed between -20 and $+20 \mathrm{deg}$, while leading-edge flaps and trailing-edge flaps were limited between 0 and +17 deg. For symmetric ailerons and trailing-edge flaps, positive signs indicate the trailing edge is deflected downward. In the case of leading-edge flaps, positive signs indictate the leading edge is deflected downward.

The algorithm was implemented as software and incorporated into an existing high-fidelity six-degree-of- 


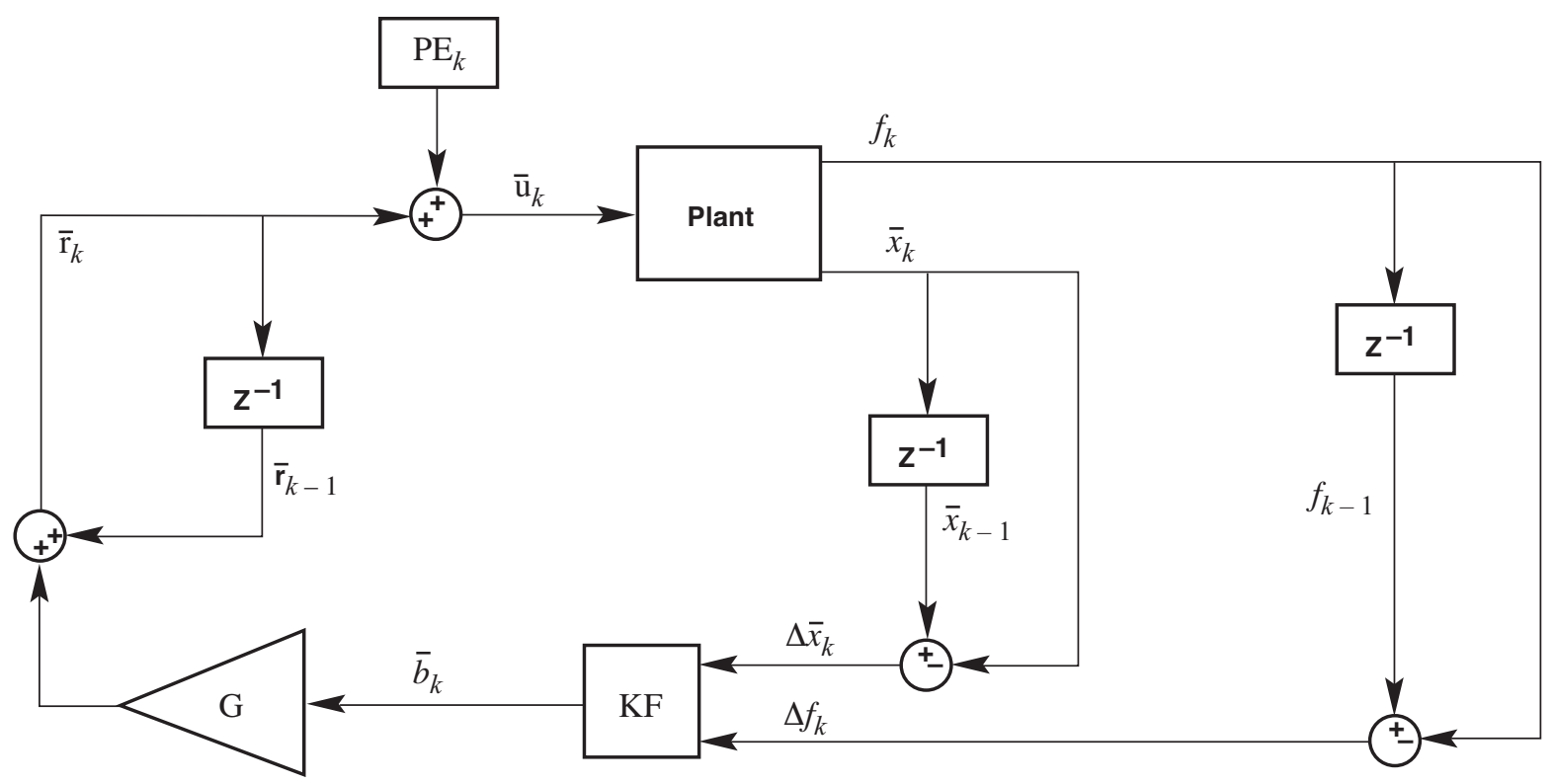

Figure 2. The peak-seeking control architecture.

freedom nonlinear simulation of the F/A-18 airplane. The simulation studies concluded that the algorithm was likely to be successful in flight. ${ }^{18}$ Encouraged by the simulation results, the reseach team turned to testing the algorithm on the actual aircraft.

\section{Flight-Test Technique}

The flight evaluation was designed to explore the behavior of the of the peak-seeking algorithm in a relevant environment. Part of the flight research approach was to initiate the algorithm from a variety of initial trim solutions at the same flight condition, and observe if the algorithm would consistently converge on a lower fuel flow trim solution. Additionally, the flight experiment was designed to explore the impacts of various tunable parameters on the behavior of the algorithm. The experiment software was designed with a large matrix of pilot-selectable initial trims and tunable parameters. The flight-test plan allowed the research engineers to decide during each flight which parameters to test on each successive test point. Also, the project was scheduled to allow for software modifications between flights.

The primary flight condition was chosen to be 240 knots calibrated airspeed (KCAS) at a pressure altitude of 25,000 ft because this was the same flight condition used for past experiments such as Autonomous Formation Flight and Autonomous Airborne Refueling Demonstration. ${ }^{25,26}$ A secondary flight condition of $200 \mathrm{KCAS}$ was added to explore the performance of the algorithm at a second condition. The research autopilot for this experiment was tuned for the primary flight condition, but happened to have adequate performance at the secondary flight condition.

All test points were conducted at the target pressure altitude of 25,000 ft. The pilot was given the option to engage at any altitude between 20,000 ft and 30,000 ft in order to avoid weather or traffic, but that option was not required for this series of research flights. Once the experiment was engaged, the research autopilot held the initial altitude until the system was disengaged. The research autopilot was designed to acquire and hold the target airspeed ( 240 or $200 \mathrm{KCAS}$ ) to improve repeatability of the flight condition. During testing, the pilots engaged the experiment at the target airspeed within $\pm 0.5 \mathrm{kn}$.

Prior to testing the closed-loop algorithm, the effects of the control surfaces on fuel flow and the noise characteristics were surveyed. This survey, called Performance Function Identification (PFI), was performed during a single flight of the F/A-18 airplane. A curve was fit to the results and predicted that the optimized trim setting would save approximately 2.5 percent fuel flow compared to the baseline trim setting, and some of the off-nominal initial trim settings would require 30 percent more fuel flow compared to the baseline. ${ }^{18}$ The estimated performance function was not made available to the algorithm, leaving the algorithm to 
determine the trim settings for minimum fuel flow. During the subsequent five flights, the algorithm was engaged a total of 22 times.

Each closed-loop algorithm test point needed roughly 20 minutes of flight time. The test points were usually terminated when the algorithm appeared to converge on a fuel flow rate; however, some test points were cut short by external circumstances.

\section{A. Ground-Test Mode}

The RFCS and ARTS have been designed with a ground-test mode that allows the system to be engaged with weight-on-wheels and idle throttle. Prior to each flight, the ground-test mode is engaged with the experiment software. The pilot and control room staff follow a procedure that exercises mission-critical research parameters on the control room displays and confirms proper operation of the research systems prior to takeoff.

\section{B. Test Procedure}

The flight-test plan used an iterative approach to exploring the behavior of the algorithm, shown as a flowchart in Fig. 3. Before starting a test point, the research engineers chose one of several planned initial configurations (IC) of trim listed in Table 1 and specific values for the various tunable parameters. In some cases the initial trim was approximately the same as the production aircraft trim (set A). In other cases the initial surface biases provided an off-nominal (more drag) trim. In Fig. 3 the example tunable parameters are the gain, $G$, and the number of measurements, $M$, used in the gradient estimation. The tunable parameter options varied from one flight to another during the flight-test campaign. After the choices were communicated, the pilot selected the appropriate mode, and then armed and engaged the algorithm.

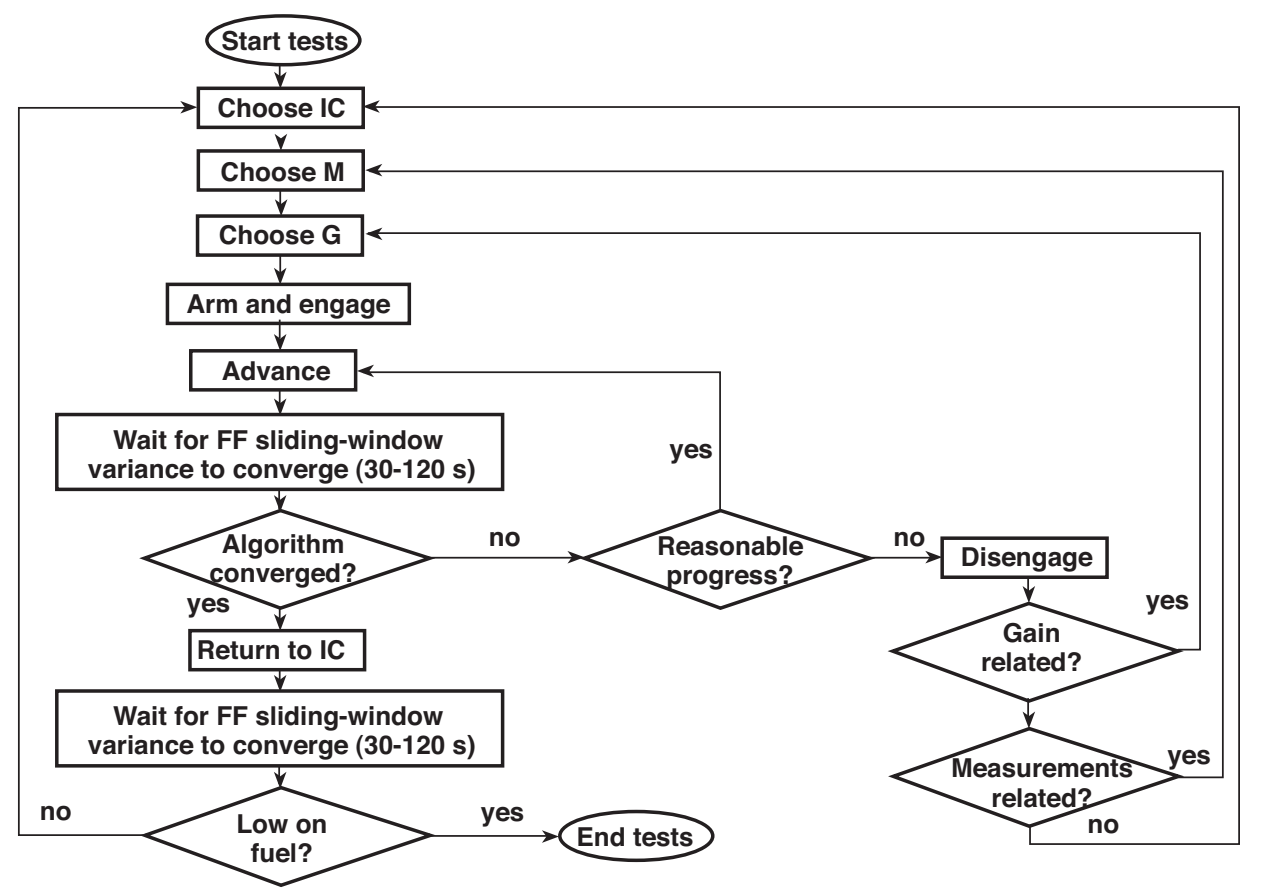

Figure 3. The algorithm evaluation plan.

The first mode selections were chosen during simulation studies prior to the flight experiment. Testing started with the simpler two-dimensional optimization scheme with the leading-edge flaps fixed at 5 deg leading-edge down, but the flight evaluation progressed to the three-dimensional optimization scheme, allowing the algorithm to additionally command leading-edge flap deflections. The initial configuration was the lowest number of measurements, $M$, found to be effective in the simulation, a moderate gain, $G$, and an initial trim bias with steep fuel flow gradient. 
Table 1. Initial effector biases in degrees.

\begin{tabular}{cccc} 
Set & Symmetric ailerons & Trailing-edge flaps & Leading-edge flaps \\
\hline A & 0 & 5 & 5 \\
B & -15 & 0 & 5 \\
C & -15 & 12 & 5 \\
D & 15 & 0 & 5 \\
E & 15 & 12 & 0 \\
F & 15 & 12 & 12
\end{tabular}

Once the algorithm was engaged, the pilot used a button to advance the algorithm one iteration at a time. This manual control of the iteration intervals was useful in the flight research environment, but would not be a feature of a production system using the algorithm. In future developments, the research team plans to automate the advancement of the algorithm making use of the experiences in this flight-test campaign.

Each iteration of the algorithm continued for 30 to $120 \mathrm{~s}$, and the usual criteria for advancing the algorithm were based on the sliding-window variance of the fuel flow measurement. The research engineers in the control room monitored the sliding-window variance of fuel flow and other parameters. In most cases the variance settled to a steady value, and a request to advance the algorithm was communicated to the pilot.

Following engagement, the algorithm started with an open-loop set of commands called the initial excitation for $M+1$ iterations. This initial excitation feeds data to the Kalman filter to be used in the first gradient estimation. Following the initial excitation the closed-loop algorithm commands are based on the gradient estimation.

After several iterations of the closed-loop algorithm, the research engineers began evaluating whether the algorithm had converged on a fuel flow rate. The anticipated pattern for the fuel flow time history is shown in Fig. 4. If not converged but still making progress, the algorithm was commanded to adavance. If no progress was observed for several iterations, the algorithm was disengaged and restarted with a different set of tunable parameters, as depicted in Fig. 3.

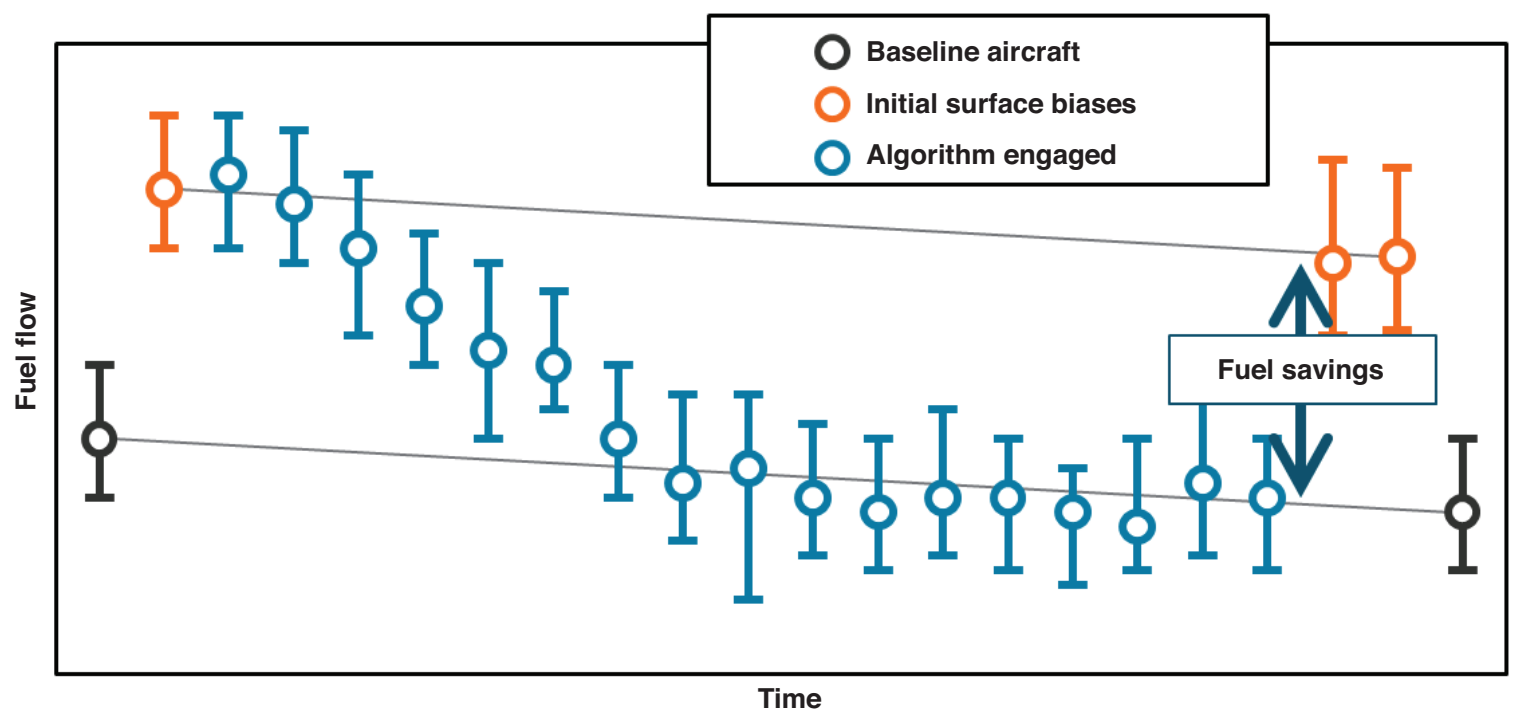

Figure 4. Illustration of a test point: Fuel flow decreasing with aircraft weight.

During the flight evaluation the research autopilots maintained altitude, airspeed, and wings-level flight, but occassionally turns were necessary to stay within the designated airspace. No algorithm advances were 
executed during the turns; however, the system remained in the engaged state.

On a typical test point, the algorithm was cycled through approximately 20 iterations. After convergence, the initial trim setting was re-inserted as a tare, as shown in Fig. 4.

A wide variety of factors have an influence on aircraft performance. Many factors, such as ambient air temperature, the energy density of the fuel, et cetera, could not be controlled, or even precisely measured, during the test. Therefore, comparisons between absolute performance between flights, or even between test points, are uncertain. Instead, the team adopted an approach of comparing the performance of the settled fuel flow of the algorithm when compared to the performance at the initial trim condition. As the aircraft burns fuel, the weight of the aircraft decreases, resulting in a lower fuel burn required to maintain speed and altitude. After the algorithm settles on a solution, the initial trim solution is re-inserted as a tare. This exposes the benefit of the algorithm, if any, compared to the initial trim setting. In most cases, the tare period was concluded after the sliding-window variance flattened out. In some cases (test points 6, 12, 16, 19, and 20) external circumstances ended the test so that a tare was not possible.

In addition to the tares at the end of each test point, additional tare points were flown before and after the closed-loop algorithm test points on each of the six research flights with the production trim setting. These tares were intended to identify the baseline fuel flow for each day of flight.

\section{Flight-Test Results}

Estimating the differences between flights, the algorithm typically gained an approximately 1- to 2-percent reduction in fuel flow compared to the baseline fuel flow after being active for several minutes. The best reduction in fuel flow seen during the flight-testing was approximately 3 percent compared to the expected fuel consumption for the weight and flight condition. These estimates are uncertain due to the variability of the performance of the airplane from one flight to another. More precise quantification of the fuel savings verus the baseline airplane would require addtional test flights. From the research team's perspective, however, the more interesting result is that the behavior of the algorithm was consistently good, as described in this section.

Table 2 lists the test configurations for all of the 22 tests. The gain is applied as depicted in the block diagram in Fig. 2. In tests with two independent effectors $(N=2)$ the effector groups were symmetric ailerons and trailing-edge flaps. In tests with three independent effector groups $(N=3)$ the effector groups were symmetric ailerons, trailing-edge flaps, and leading-edge flaps. In all cases, stabilators and throttle setting were dependent effectors. The signal used as the performance metric on most tests was the average of the two research fuel flow (research FF) meters. In tests 9, 14, and 21, alternative performance functions of power level angle or production fuel flow (production FF) were selected to explore the possibility of using production sensors with the algorithm, as discussed below. $M$ is the number of measurements used by the Kalman filter. The "window" is the duration in seconds of the sliding-window time averaging used to smooth the fuel flow data.

The inner-loop controller and research autopilot feedback loops strictly maintained airspeed and altitude throughout the tests. Barometric altitude was maintained within $\pm 8 \mathrm{ft}$, and dynamic pressure was maintained within $\pm 1 \mathrm{lb} / \mathrm{ft}^{2}$.

Four different comparisons are discussed, with each comparison utilizing figures of the same three types. The figure citations fit in the following matrix:

\begin{tabular}{lcccc} 
Comparison & $\begin{array}{c}\text { Test numbers } \\
\text { (see Table 2) }\end{array}$ & $\begin{array}{c}\text { Fuel flow versus } \\
\text { algorithm } \\
\text { iterations }\end{array}$ & $\begin{array}{c}\text { Effector } \\
\text { Ailerons versus } \\
\text { trailing-edge } \\
\text { flaps }\end{array}$ & $\begin{array}{c}\text { positions versus } \\
\text { algorithm } \\
\text { iterations }\end{array}$ \\
\hline Nominal results & 1,2 , and 3 & Fig. 5 & Fig. 6 & Fig. 7 \\
Initial configuration A & $5,6,7$, and 22 & Fig. 8 & Fig. 9 & Fig. 10 \\
Varying flight condition & $10,13,18,19$, and 20 & Fig. 11 & Fig. 12 & Fig. 13 \\
Performance metrics & $2,9,14$, and 21 & Fig. 14 & Fig. 15 & Fig. 16
\end{tabular}

In figures $5,8,11$, and 14 , the fuel flow rate has been normalized with respect to the baseline fuel flow of the production F/A-18 trim configuration. The baseline fuel flow is estimated from the PFI tares data, 
detrended for the weight of the airplane. Positive percentages of fuel flow indicate increased fuel consumption relative to the baseline $\mathrm{F} / \mathrm{A}-18$ trim solution, and negative percentages indicate fuel savings compared to what the airplane would have consumed if the algorithm had not been engaged. Note that the baseline fuel flow estimate is based on a different flight than the closed-loop algorithm test flights, and many conditions affecting fuel efficiency are not accounted for. Unfortunately, a technical problem prevented some baseline trim tare data from being recorded toward the end of some flights. In lieu of those baseline trim tares and to better align the different test runs in the vertical axis, the performance function surface fit from the PFI test data was used to predict the fuel flow for each combination of surface deflections (dotted lines in figures 5,8 , and 14). A vertical offset is computed from the differences between the measured and predicted fuel flows. This calculation involves significant uncertainty. Additional flight-test data and a more strictly controlled experiment are required for a more precise comparison between test runs. The PFI test did not survey the 200-KCAS flight condition, so no performance function prediction is available for Fig. 11. The baseline trim tares were recorded before and after each of the 200-KCAS test points, however, and those tares are used to align the results in Fig. 11 for comparison.

In figures $6,9,12$, and 15 the point markers indicate the algorithm commands with the persistent excitation added. The solid lines indicate the algorithm commands without the persistent excitation. In these plots, the vertical and horizontal axes represent deflections of leading-edge flaps and symmetric ailerons; however, deflections of leading-edge flaps would require a third axis that has been omitted for visual clarity. Figures 7, 10, 13, and 16 show the deflections of all the relevant effectors and the aircraft angle of attack.

Table 2. Test configurations flown.

\begin{tabular}{ccccccrrr} 
Test & Flight & KCAS & Performance function, $f$ & IC set (see Table 1) & $N$ & Window, s & $M$ & $G$ \\
\hline 1 & 1 & 240 & Research FF & C & 2 & 20 & 5 & -118 \\
2 & 1 & 240 & Research FF & B & 2 & 20 & 3 & -118 \\
3 & 1 & 240 & Research FF & D & 2 & 20 & 5 & -177 \\
4 & 1 & 240 & Research FF & F & 3 & 20 & 5 & -118 \\
5 & 2 & 240 & Research FF & A & 3 & 20 & 5 & -118 \\
6 & 2 & 240 & Research FF & A & 3 & 20 & 5 & -53 \\
7 & 2 & 240 & Research FF & A & 3 & 20 & 7 & -118 \\
8 & 2 & 240 & Research FF & E & 3 & 20 & 5 & -118 \\
9 & 3 & 240 & Power lever angle & B & 2 & 20 & 3 & -118 \\
10 & 3 & 200 & Research FF & B & 2 & 20 & 3 & -118 \\
11 & 3 & 240 & Research FF & A & 3 & 10 & 10 & -59 \\
12 & 3 & 240 & Research FF & A & 3 & 40 & 3 & -118 \\
13 & 4 & 200 & Research FF & B & 3 & 20 & 3 & -118 \\
14 & 4 & 240 & Power lever angle & B & 2 & 20 & 3 & -118 \\
15 & 4 & 240 & Research FF & A & 3 & 10 & 10 & -133 \\
16 & 4 & 240 & Research FF & A & 3 & 20 & 10 & -133 \\
17 & 4 & 240 & Research FF & A & 3 & 40 & 3 & -118 \\
18 & 5 & 200 & Research FF & F & 3 & 40 & 5 & -118 \\
19 & 5 & 200 & Research FF & F & 3 & 40 & 5 & -266 \\
20 & 5 & 200 & Research FF & A & 3 & 20 & 5 & -118 \\
21 & 5 & 240 & Production FF & B & 2 & 40 & 5 & -118 \\
22 & 5 & 240 & Research FF & A & 3 & 40 & 5 & -118
\end{tabular}

\section{A. Nominal Results}

The first three test runs, shown in Fig. 5 through Fig. 7, of the peak-seeking algorithm demonstrated good performance and matched expectations based on the earlier PFI test flight data and the simulation results. The downward slopes in Fig. 5 illustrate that the algorithm quickly converges on a lower fuel flow trim 
solution, and the relatively flat tail ends show that the algorithm maintains the low fuel flow performance while it continues to seek better trim solutions.

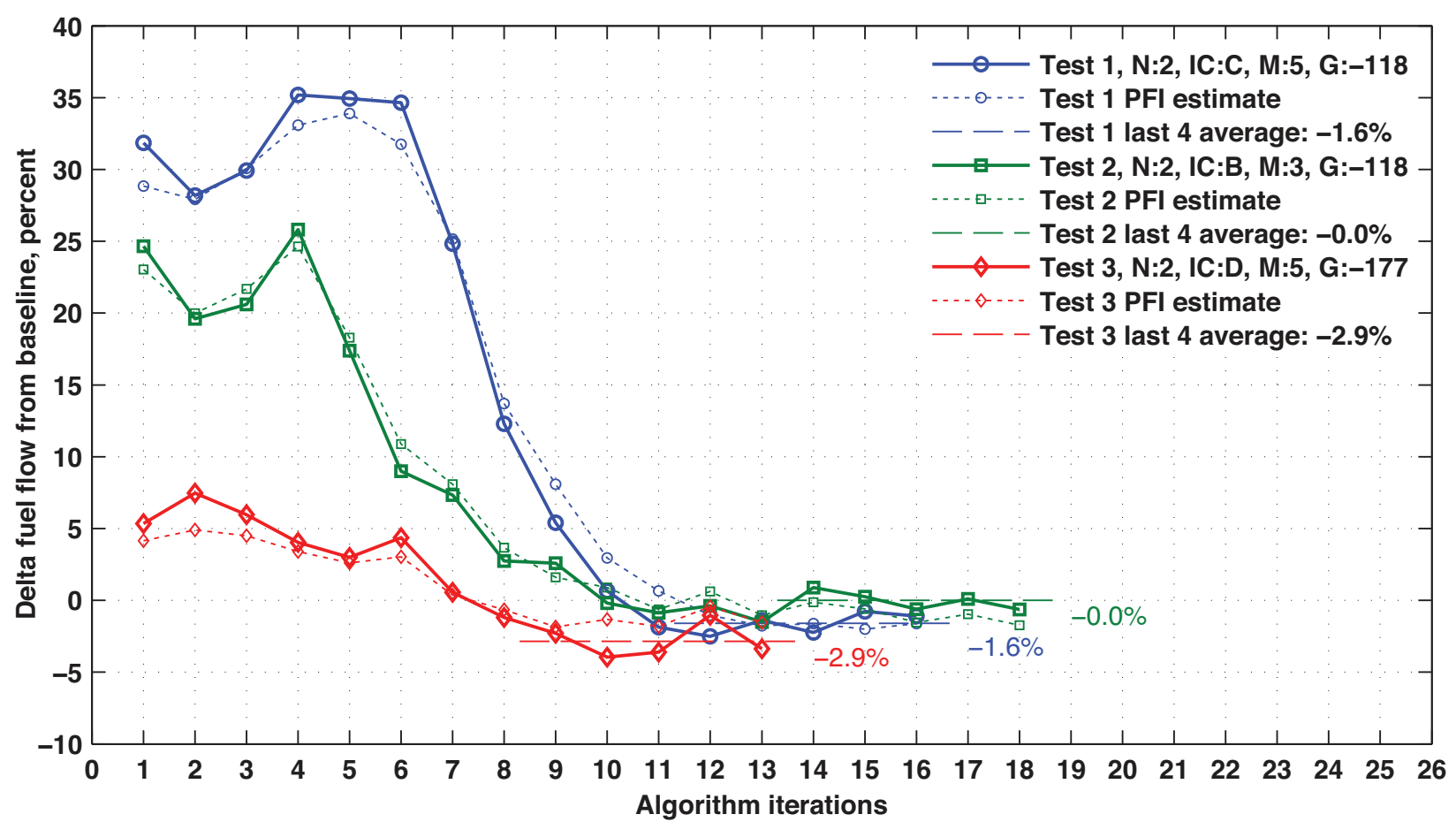

Figure 5. Fuel flow versus algorithm iterations, first three tests.

The first three tests used only two groups of effectors: symmetric ailerons and trailing-edge flaps. Each test run was started from a different initial set of surface positions: Sets C, B, and D in Table 1. After the initial four or six iterations (the initial excitation phase) the algorithm quickly converged to a lower-drag configuration, taking roughly five minutes. Within five iterations of the closed-loop algorithm, the fuel flow settled to near its minimum (adjusted for the weight of the airplane in all of the subsequent plots.)

Note that the zig-zag pattern in Fig. 6 and Fig. 7, as well as in figures 9, 10, 12, 13, 15, and 16, is due to the persistent excitation. The function for the persistent excitation is explained in the companion paper. ${ }^{18}$

In several tests at the 240-KCAS flight condition, the algorithm eventually commanded approximately $5 \mathrm{deg}$ bias in symmetric ailerons and approximately $4 \mathrm{deg}$ bias in trailing-edge flaps regardless of the initial surface biases (for example, Fig. 7). In another view, Fig. 6, the final positions of the surfaces appear near the predicted sweet spot, which is the predicted lowest fuel consumption configuration based on the PFI testing that preceded the closed-loop experiment. These trends toward similar trim configurations indicate that the algorithm may be re-discovering the minimum fuel flow configuration regardless of the initial condition.

\section{B. Initial Configuration Set A}

Figure 8 through Fig. 10 show selected tests 5, 6, 7, and 22, each initiated with effector bias set A. Initial effector position set $\mathrm{A}$ is similar to the baseline F/A-18 trim allocation. As the algorithm runs for roughly 10 min, slight improvements in fuel flow are seen in a few test runs. In other test runs it is unclear if fuel flow is reduced; however, the algorithm commands remained near the sweet spot, which is the desired behavior.

\section{Varying Flight Condition}

While most tests were run at $240 \mathrm{KCAS}$, five test points were run at an alternative flight condition of $200 \mathrm{KCAS}$. In these five test runs (test numbers 10, 13, 18, 19, and 20) the shape of the performance function is likely to be different from the 240-KCAS flight condition. Tares were recorded with the baseline trim configuration at $200 \mathrm{KCAS}$ on flights 4 and 5, but the lack of 200-KCAS data points in the PFI flight data makes comparisons between the two flights less certain compared to the 240-KCAS test points. In each 


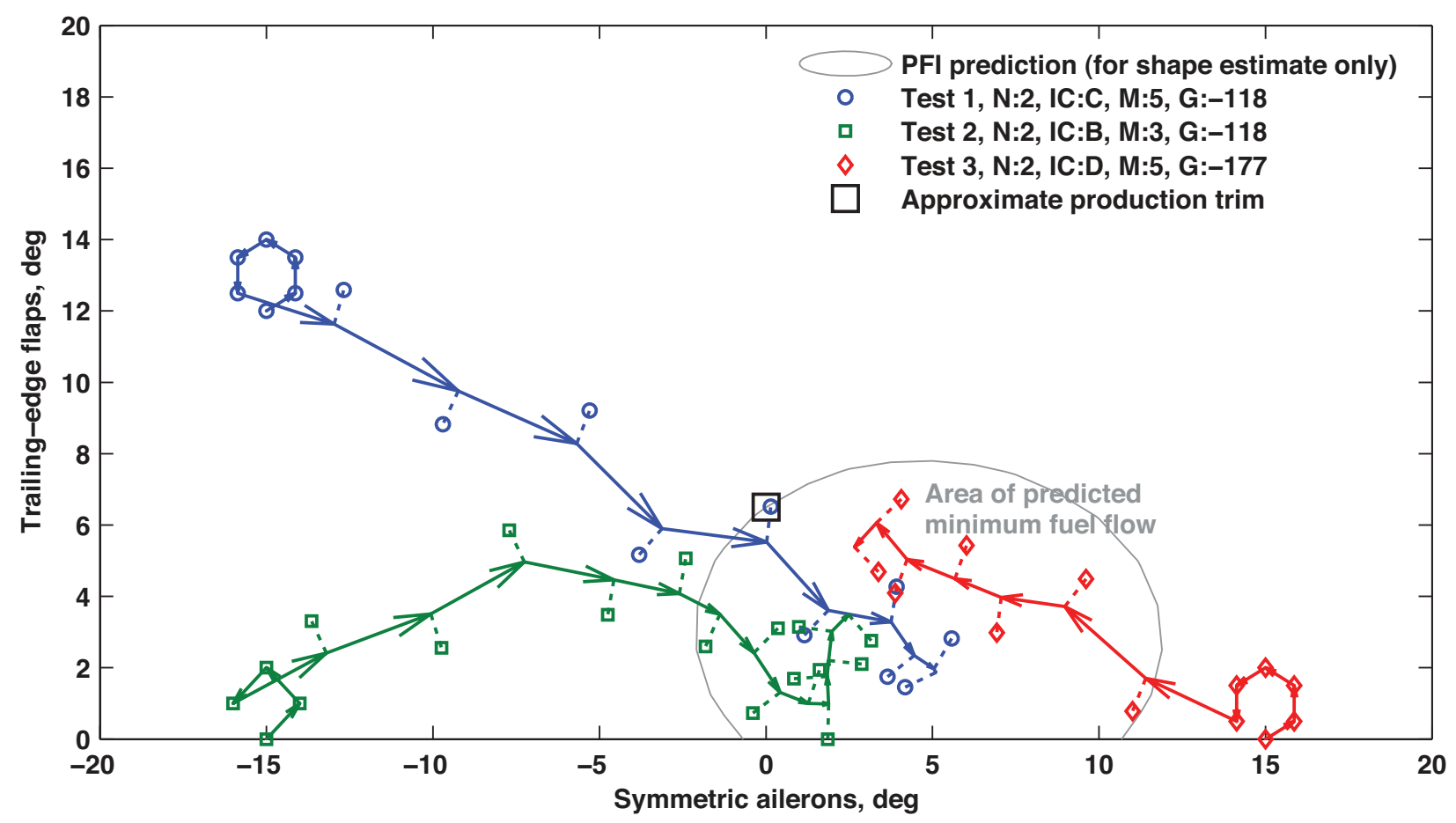

Figure 6. Trajectories across performance function, first three tests.

of these cases, shown in Fig. 11 through Fig. 13, the algorithm converged on a reduced fuel flow, but the final set of surface positions was less consistent. There is the possibility that there are multiple local minima at this condition, or the gradient is very flat at the bottom of this performance function. Additional test data are needed to draw a conclusion.

\section{Alternative Performance Metrics}

During most tests, measurements of fuel flow from research flow meters were fed to the algorithm as the performance metric. Since most fleet aircraft are not equipped with specialized research instrumentation, the team was interested in alternative performance metrics that are more common on fleet aircraft. Power lever angle, also known as throttle position, was the performance measurement used on tests 9 and 14 . On test 21, the F/A-18 production flow meters were used as the source of the performance function. Test 2 is included for comparison to the performance of the algorithm using the research flow meters. The performance metrics were normalized for input to the algorithm, but the same tunable parameters were used for each performance metric. No re-tuning was performed for the selected performance metrics. Each of these four cases was initiated from the same set of initial surface positions, set B. In each of these cases the algorithm performed well, shown in Fig. 14 through Fig. 16. The algorithm consistently converged on a set of surface positions with a lower fuel burn and the solutions were similar. Convergence was achieved in approximately 6 to 10 iterations of the algorithm. For test 21, a 40-s time-averaging window was chosen. For the other tests $(2,9$, and 14$)$ a 20 -s time-averaging window was used.

\section{E. Varying Tunable Parameters}

One aspect of the experiment was to explore the impacts of some tunable parameters that were available to the algorithm designer. With improved intuition into the effects, it is possible to improve the performance of the algorithm. One aspect for good performance is that the algorithm rejects noise and consistently returns to similar solution. Secondly, good performance means that the algorithm converges quickly as conditions change and does not linger at poor trim configurations.

Changing the number of measurements, $M$, used in each estimation of the gradient to 3,5 , or 7 had little impact on the performance of the algorithm. Future implementations of this algorithm with more effectors 

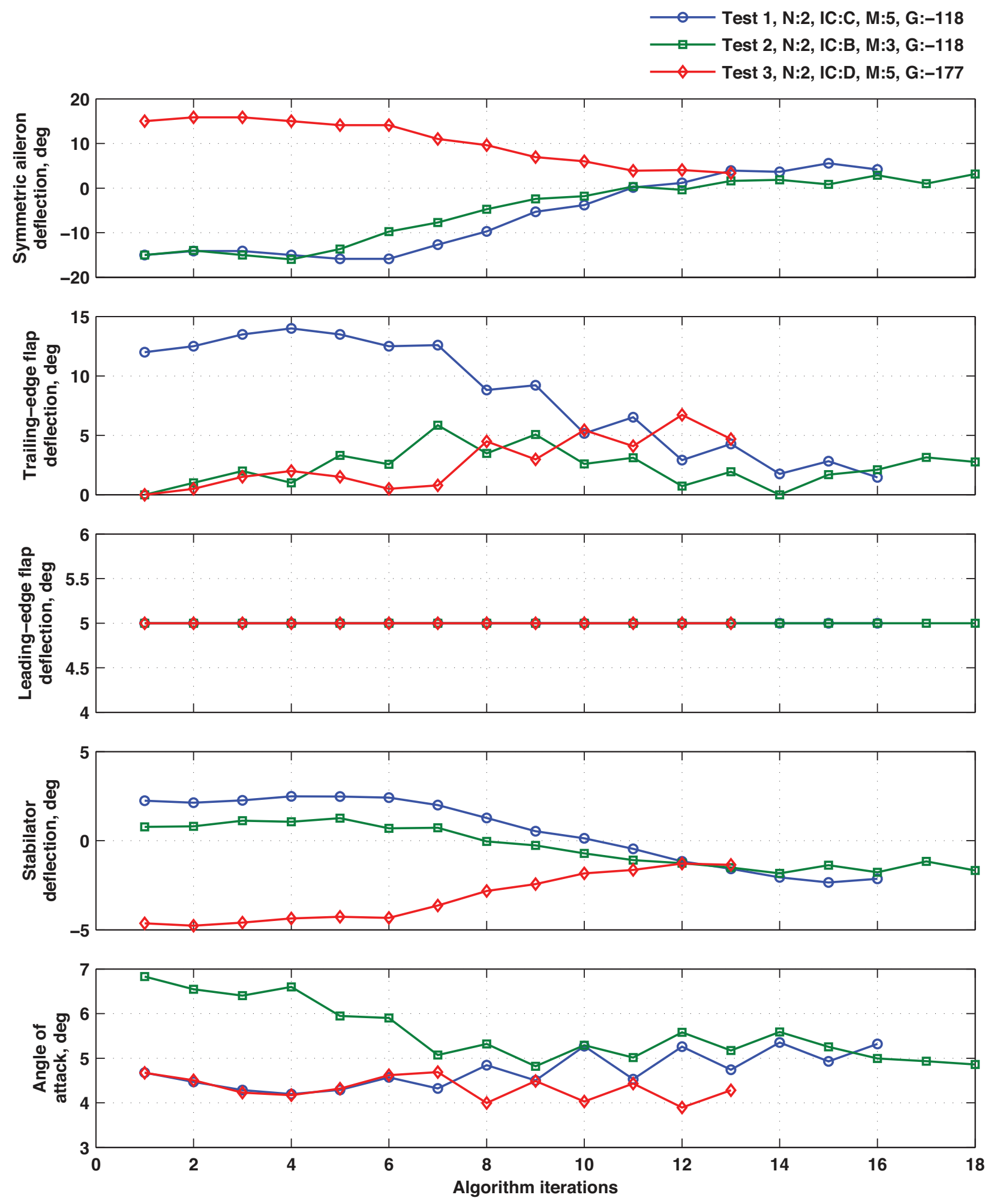

Figure 7. Effector positions versus algorithm iterations, first three tests. 


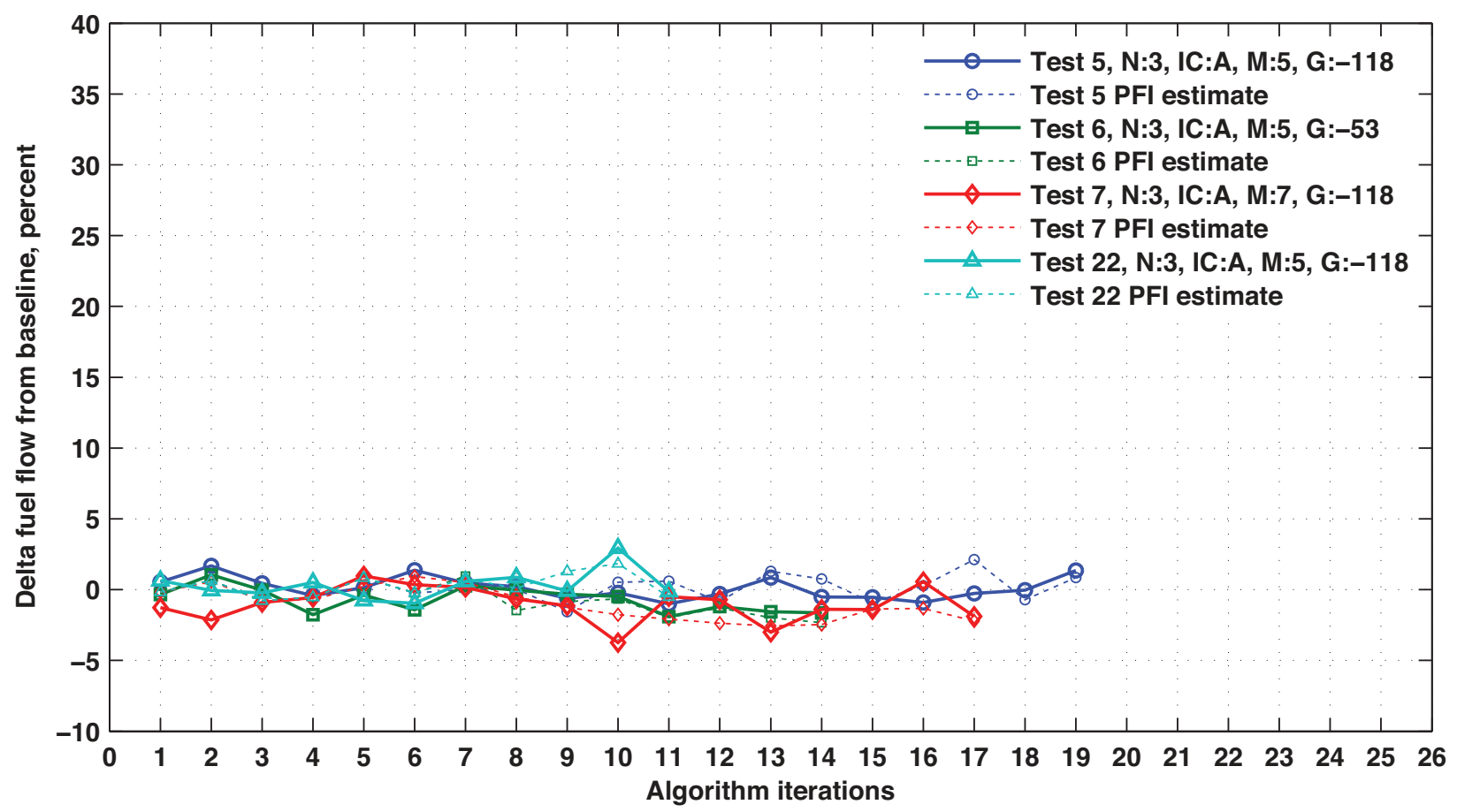

Figure 8. Fuel flow versus algorithm iterations, selected tests with initial configuration set A.

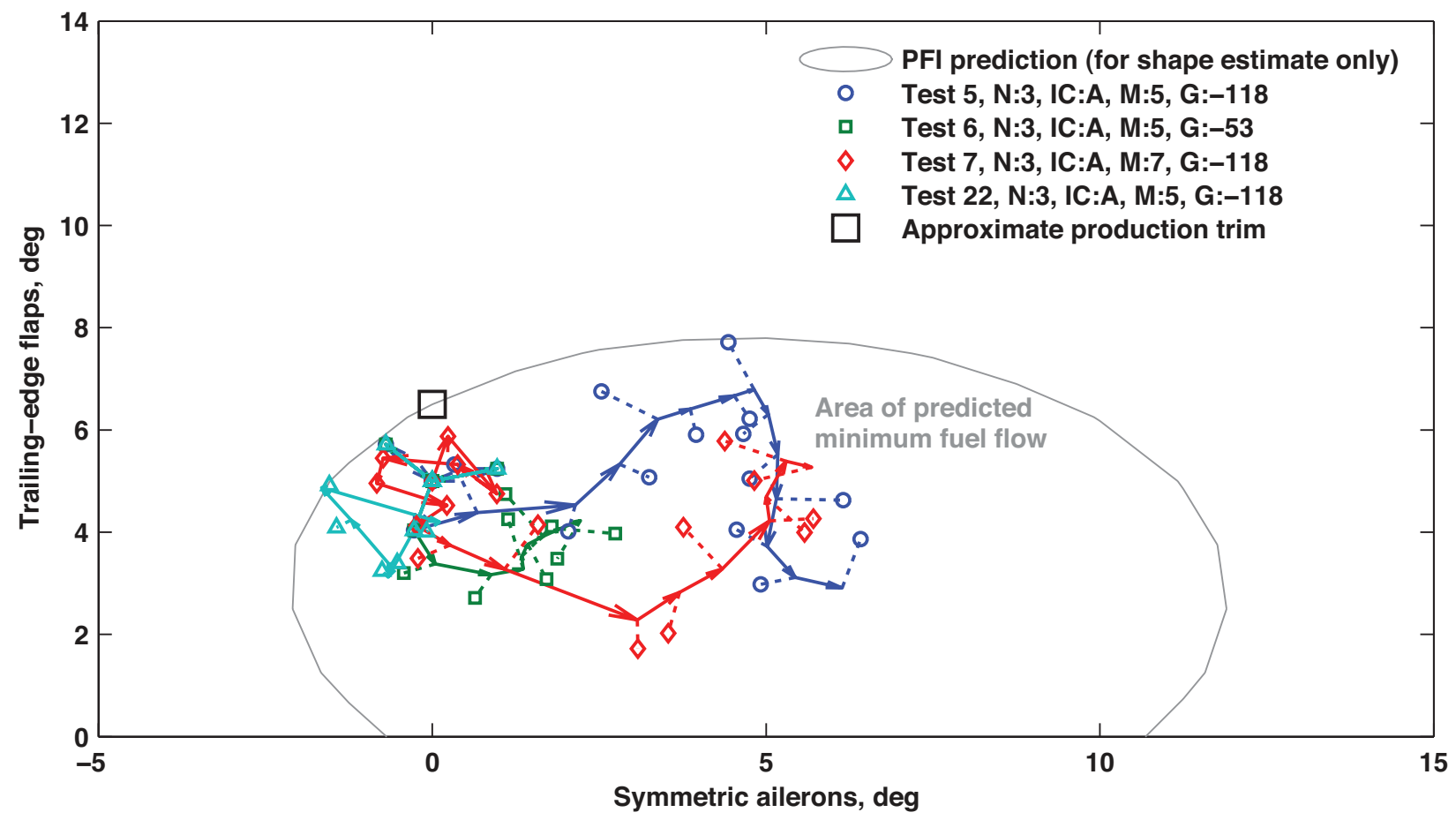

Figure 9. Trajectories across performance function, selected tests with initial configuration set A. 

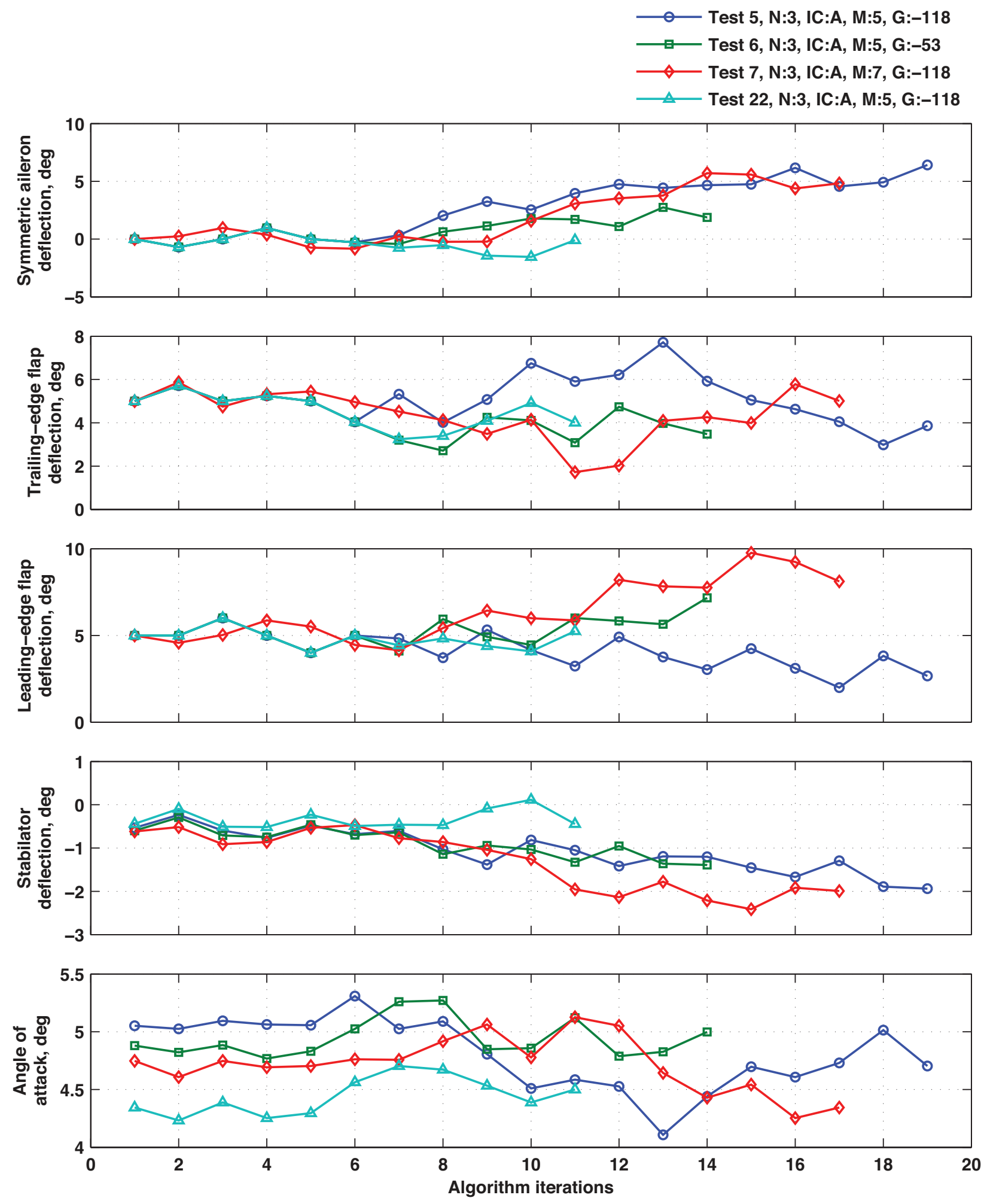

Figure 10. Effector positions versus algorithm iterations, selected tests with initial configuration set $\mathbf{A}$. 


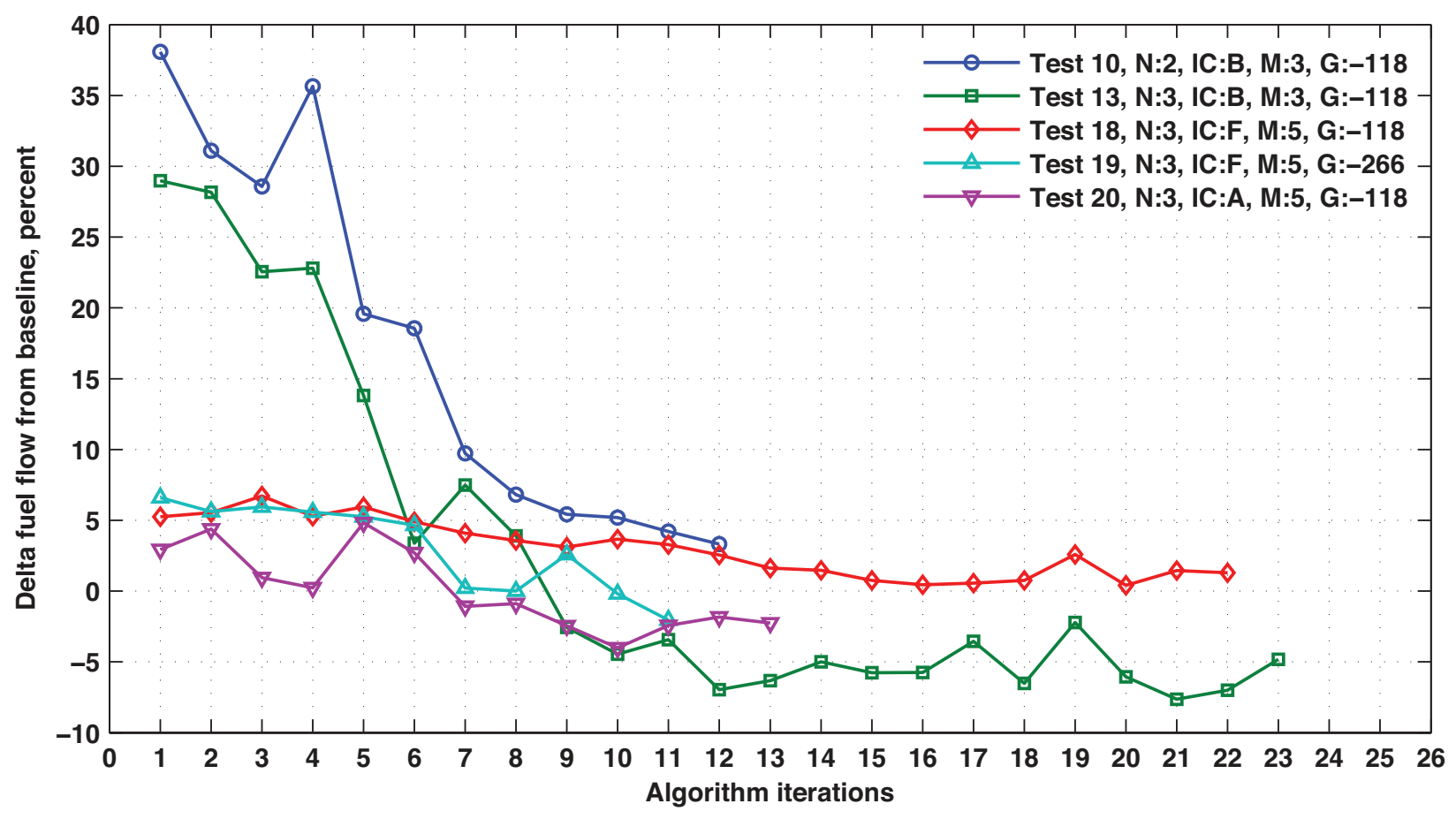

Figure 11. Fuel flow versus algorithm iterations, at 200 KCAS.

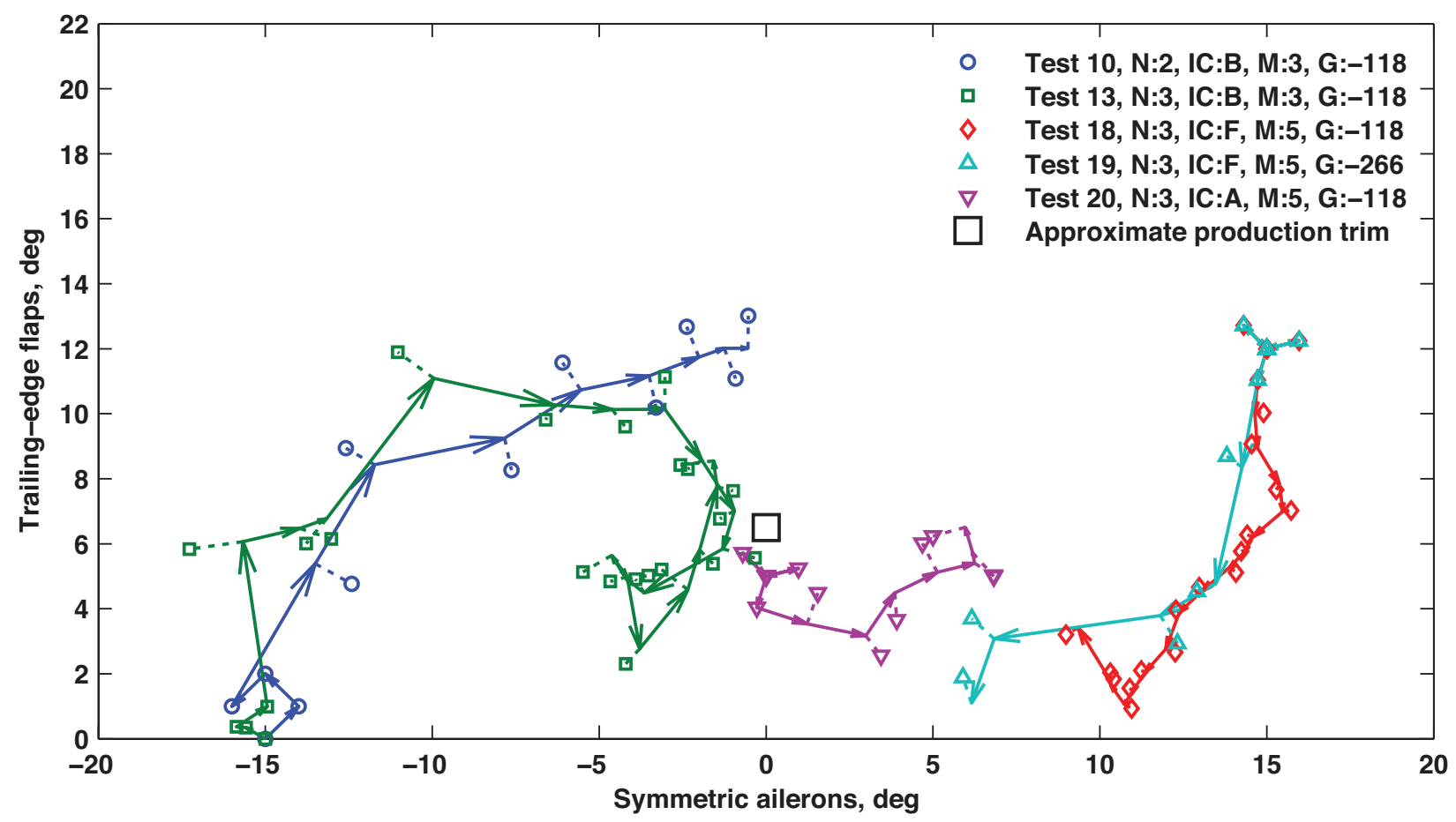

Figure 12. Trajectories across performance function, at 200 KCAS. 
- Test 10, N:2, IC:B, M:3, G:-118

Test 13, N:3, IC:B, M:3, G:-118

Test 18, N:3, IC:F, M:5, G:-118

Test 19, N:3, IC:F, M:5, G:-266

Test 20, N:3, IC:A, M:5, G:-118
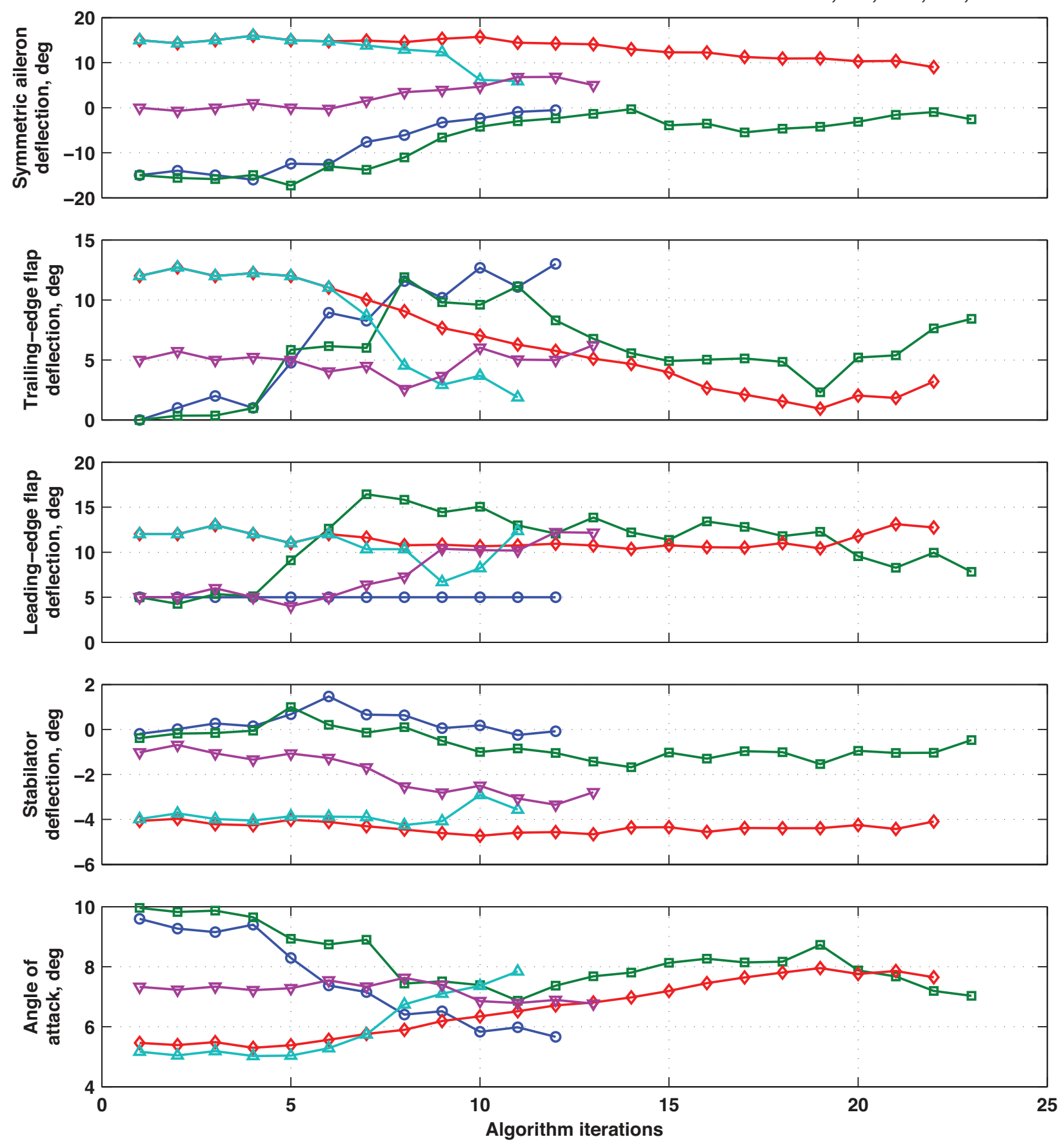

Figure 13. Effector positions versus algorithm iterations, at $200 \mathrm{KCAS}$. 


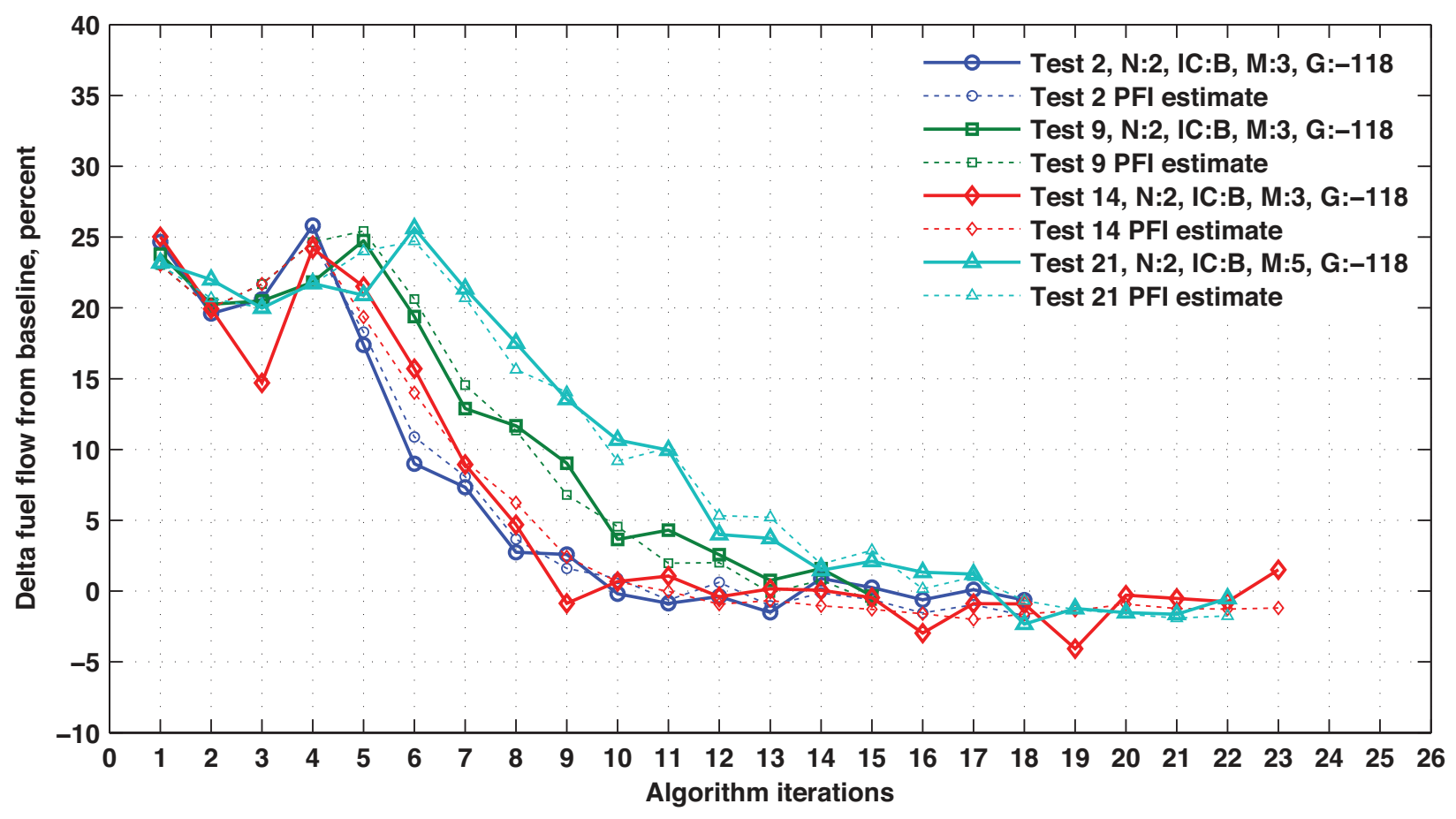

Figure 14. Fuel flow versus algorithm iterations, with various performance metrics.

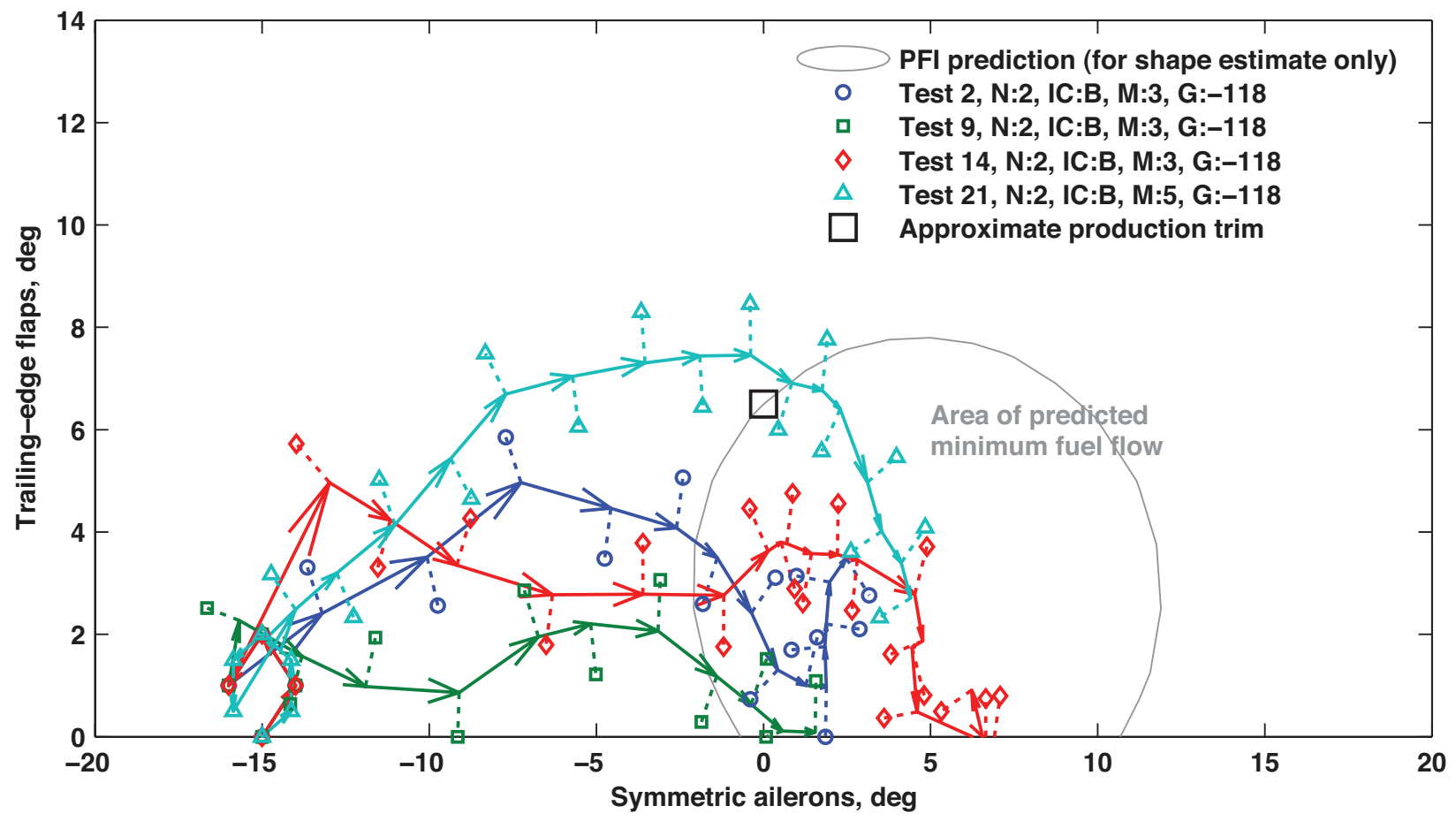

Figure 15. Trajectories across performance function, with various performance metrics. 

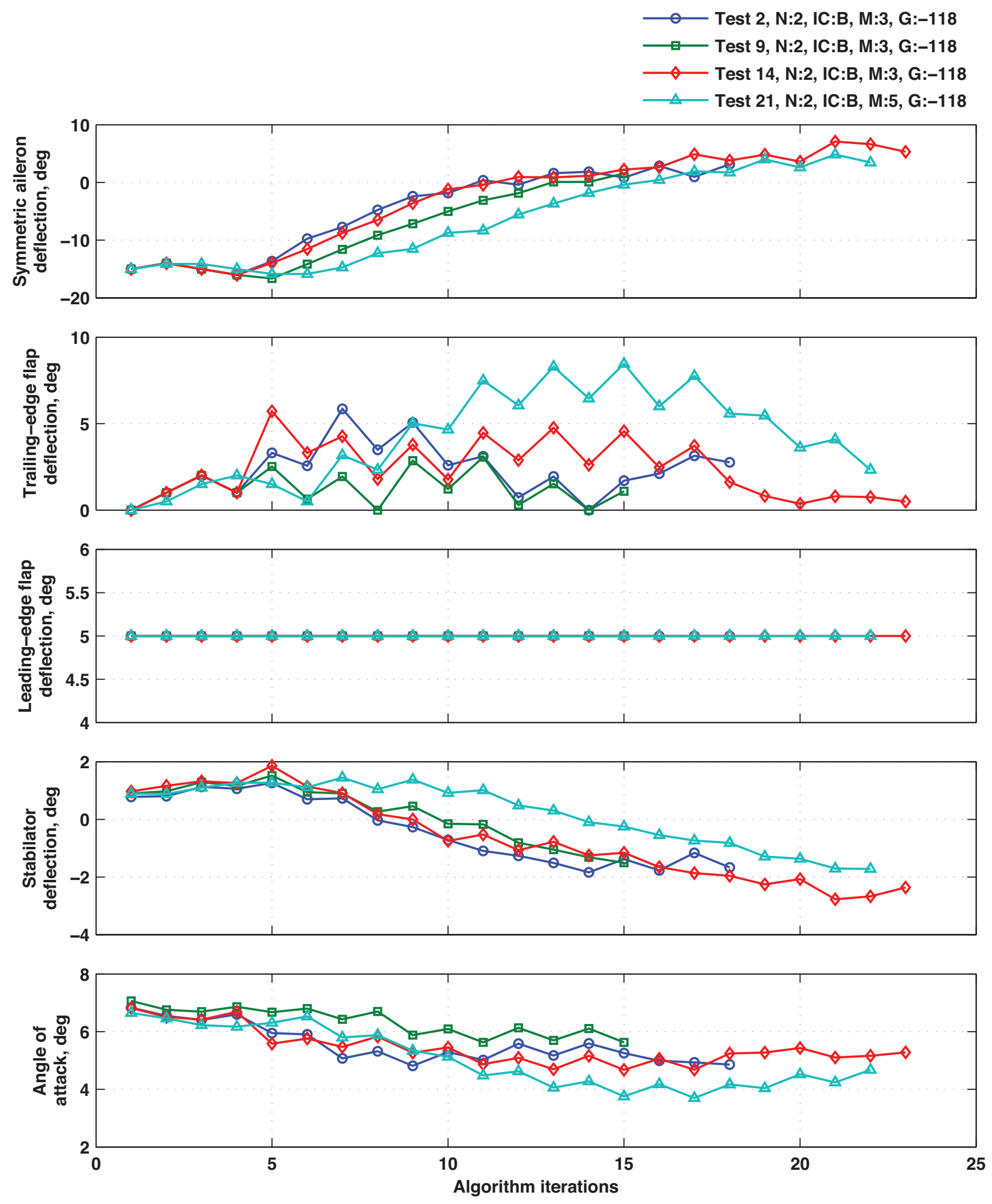

Figure 16. Effector positions versus algorithm iterations, with various performance metrics. 
may need higher numbers of measurements for gradient estimation.

Of the various gains used during the tests, the nominal gain performed best. Lesser magnitude gains resulted in adequate performance, but slower convergence. Larger magnitude gains generally did not result in faster convergence. The nominal gains were chosen during the simulation study that preceded the flight experiment, which suggests that the simulation was fairly accurate in its representation of the performance function gradient and the noise characteristics on the feedback signal.

Setting the performance function time-averaging window to $10 \mathrm{~s}$ prevented the algorithm from making good estimates of the performance function gradient. Using longer time-averaging windows gave better results. While longer time-averaging windows require more time, it is hoped that fleet aircraft using a similar algorithm would have ample time for time-averaging windows to reject noise and disturbances, while still converging on an improved trim solution.

By happenstance, all of the flight tests were flown in smooth air. Only in a few cases was the pilot able to feel atmospheric disturbances. In most cases the pilots reported no noticeable turbulence. In the other cases they reported very mild turbulence. When asked to comment on ride quality, all of the pilots said the effects of the algorithm were minimal. For example: "I did notice some low frequency movement on the first flight. It wasn't bad and eventually only noticed when I 'looked for it'. And when I 'looked for it' I didn't always find it."

\section{Concluding Remarks}

A project at the NASA Dryden Flight Research Center explored the practical application of a real-time trim optimization algorithm for reduced fuel consumption. A flight research campaign of six flights was conducted to test a peak-seeking control algorithm. The algorithm directly added biases to the deflection of symmetric ailerons, trailing-edge flaps, and leading-edge flaps of a modified F/A-18 airplane. A nonlinear dynamic inversion inner-loop controller and research autopilot responded to the new configuration by changing the position of the horizontal stabilators, the angle of attack of the airplane, and the throttles. The algorithm found a trim configuration that required approximately 3 percent less fuel flow than the baseline trim at the given flight condition. The algorithm consistently converged on a low fuel flow trim configuration from several different initial configurations. The performance of the algorithm was adequate with production instrumentation and at different flight conditions without re-tuning the algorithm parameters. Research-grade instrumentation is not a requirement. The present design performed well at both flight conditions that were tested. The pilots could rarely feel the effects of the algorithm, and only when they actively looked for those effects. Ride quality was not impacted by the algorithm.

The peak-seeking algorithm behavior was encouraging, although the scope of the flight research campaign was limited to a single airplane and two flight conditions. The researchers gained valuable intuition regarding the design and tuning of the peak-seeking algorithm. Future flight research could help mature this technology and transition it to other aircraft.

\section{Future Research}

While the F/A-18 flight results are encouraging, a major goal for this technology is to reduce emissions from commercial airliners and freighters. Based on this work and prior work with an L-1011 airplane by Gilyard et al., there are opportunities for transport aircraft trim to be improved with a real-time algorithm. The new approach presented in this paper might present additional improvement over the single-effector Gilyard approach by optimizing multiple effectors simultaneously.

Military and science aircraft often carry external stores that have a substantial influence on trim. Many commerical airliners are now equipped with blisters for in-flight entertainment systems and other systems. In-flight optimization may substantially improve performance for configurations that differ from the original production configuration and eschew complex flight-test programs. If improvement can be made from altering trim configuration, this algorithm can likely find the minimum fuel flow trim.

In the initial flight research phase, the algorithm was limited to longitudinal effectors in order to limit the complexity of the design process and the experiment. For a variety of reasons, many aircraft are asymmetric. Manufacturing tolerances, external stores, repairs, different performance from multiple engines, and many other sources of asymmetry may have significant impact on lateral-directional trim solutions and apparent sideslip. Leveraging a peak-seeking control approach for all aircraft axes is likely to be fruitful, but 
investigation is necessary.

The initial flight research phase was entirely subsonic. The possibility of real-time trim optimization in supersonic flight has not yet been investigated. Modification of the longitudinal lift distribution of the aircraft can change wave drag.

By happenstance, each of the test flights were conducted in smooth air with very little turbulence. It will be necessary to investigate the impact of moderate or heavy turbulence on the algorithm's performance and to design mitigations to those impacts.

Aging aircraft become more flexible and change shape due to maintenance and repairs. These changes to the outer mold line and surface deflections are likely to change the minimum fuel-flow trim configuration. Some of that loss in fuel efficiency may be re-attainable through online trim optimization, but the magnitude of these impacts requires further study.

The potential fuel-saving benefits of a peak-seeking control algorithm are expected to vary depending on the aircraft platform. Also, the cost and complexity of retrofitting an aircraft for in-flight trim optimization will depend on the specific systems of that aircraft. Further flight research is needed to generate guidelines for engineers considering implementation of such an algorithm on other aircraft.

\section{References}

\footnotetext{
${ }^{1}$ Collier, F., "Overview of NASA's Environmentally Responsible Aviation Project," 48th AIAA Aerospace Sciences Meeting, Jan. 2010.

${ }^{2}$ Federal Aviation Administration, "FAA Aerospace Forecast Fiscal Years 2013-2033," 2013, p. 115.

${ }^{3}$ U.S. Environmental Protection Agency, "Inventory of U.S. Greenhouse Gas Emissions and Sinks: 1990-2011," April 2013, pp. 3-19-3-20.

${ }^{4}$ Wagner, M., and Norris, G., Boeing 787 Dreamliner, MBI Publishing Company, 2009.

${ }^{5}$ Thomson, K., and Schulze, E. T., "Delivering Fuel and Emissions Savings for the 777," 2009, http://www.boeing.com/ commercial/aeromagazine/articles/qtr_03_09/pdfs/AERO_Q309_article02.pdf, accessed July 15, 2013.

${ }^{6}$ Francheska, A., "Boeing aids United Airlines in modifying its 777 fleet for fuel efficiency," International Business Times, March 2011, http://au.ibtimes.com/articles/125677/20110323, accessed July 15, 2013.

${ }^{7}$ Orme, J. S., and Schkolnik, G. S., "Flight Assessment of the Onboard Propulsion System Model for the Performance Seeking Control Algorithm on an F-15 Aircraft," NASA TM-4705, 1995.

${ }^{8}$ Orme, J. S., and Conners, T. R., "Supersonic Flight Test Results of a Performance Seeking Control Algorithm on a NASA F-15 Aircraft," AIAA 94-3210, June 1994.

${ }^{9}$ Schkolnik, G. S., "Identification of Integrated Airframe-Propulsion Effects on an F-15 Aircraft for Application to Drag Minimization," AIAA-1993-3764, Jan. 1993.

${ }^{10}$ Gilyard, G. B., and Orme, J. S., "Subsonic Flight Test Evaluation of a Performance Seeking Control Algorithm on an F-15 Airplane," NASA TM-4400, 1992.

${ }^{11}$ Gilyard, G. B., Georgie, J., and Barnicki, J. S., "Flight Test of an Adaptive Configuration Optimization System for Transport Aircraft," NASA TM-1999-206569, 1999.

${ }^{12}$ Gilyard, G. B., "In-Flight Adaptive Performance Optimization (APO) Control Using Redundant Control Effectors of an Aircraft," US Patent No. 5,908,176, June 1, 1999.

${ }^{13}$ Krieger, J. P., and Krstic, M., "Extremum Seeking Based on Atmospheric Turbulence for Aircraft Endurance," J. of Guidance, Control, and Dynamics, Vol. 34, No. 6, 2011, pp. 1876-1885.

${ }^{14}$ Ryan, J., and Speyer, J. L., "Peak-Seeking Control Using Gradient and Hessian Estimates," Proceedings of the 2010 American Control Conference, CFP10ACC-PRT, June 30, 2010, pp. 611-616, http://hdl.handle.net/2060/20100024511, accessed July 15, 2013.

${ }^{15}$ Binetti, P., Ariyur, K. B., Krstic, M., and Bernelli, F., "Formation Flight Optimization Using Extremum Seeking Feedback," J. of Guidance, Control, and Dynamics, Vol. 26, No. 1, 2003, pp. 132-142.

${ }^{16}$ Hanson, C., and Ryan, J. J., "Peak-Seeking Optimization of Spanwise Lift Distribution for Wings in Formation Flight," AIAA 2012-4692, Aug. 2012.

${ }^{17}$ Griffin, B. J., Brown, N. A., and Yoo, S. Y., "Intelligent Control for Drag Reduction on the X-48B Vehicle," AIAA 2011-6470, Aug. 2011.

${ }^{18}$ Schaefer, J. and Brown, N., "Peak-Seeking Optimization of Trim for Reduced Fuel Consumption: Architecture and Performance Predictions," AIAA Guidance, Navigation, and Control Conference, AIAA, Reston, Virginia, Aug. 2013, (submitted for publication).

${ }^{19}$ Ryan, J. J., and Speyer, J. L., "Systems and Methods for Peak-Seeking Control," US Patent No. 8,447,443, May 21, 2013.

${ }^{20}$ Hanson, C., "Capability Description for NASA's F/A-18 TN 853 as a Testbed for the Integrated Resilient Aircraft Control Project," DFRC-IRAC-CAP-002, 2009, http://hdl.handle.net/2060/20090022324, accessed July 15, 2013.

${ }^{21}$ Cobleigh, B. R., "Sole Source Justification for F-404 Engine Instrumentation Kit for AFF Project," NASA PR\# P-0-RA00204, Autonomous Formation Flight Project internal document, Dryden Flight Research Center, Edwards, California, July 2000.

${ }^{22}$ Hadaller, O. J., and Johnson, J. M., "World Fuel Sampling Program," CRC Report No. 647, 2006.

${ }^{23}$ Miller, C. J., "Nonlinear Dynamic Inversion Baseline Control Law: Architecture and Performance Predictions," AIAA 2011-6467, Aug. 2011.
} 
${ }^{24}$ Miller, C. J., "Nonlinear Dynamic Inversion Baseline Control Law: Flight-Test Results for the Full-scale Advanced Systems Testbed F/A-18 Airplane," AIAA 2011-6468, Aug. 2011.

${ }^{25}$ Hanson, C. E., Ryan, J., Allen, M. J., and Jacobson, S. R., "An Overview of Flight Test Results for a Formation Flight Autopilot," NASA TM-2002-210729, 2002.

${ }^{26}$ Dibley, R. P., Allen, M. J., and Nabaa, N., "Autonomous Airborne Refueling Demonstration, Phase I Flight-Test Results," NASA TM-2007-214632, 2007. 